\title{
Valor predictivo de proteína $C$ reactiva y albúmina en la expulsión de litos ureterales de 6-10 mm del tercio inferior
}

\section{Predictive Value of C-reactive Protein and Albumin in the Expulsion of Ureteral Stones $(6-10 \mathrm{~mm})$ from the Lower Third}

\author{
Enrique Omar Piñón Solis ${ }^{1}$ J José Fernando Gil García ${ }^{1}$ Edgar Alejandro Medrano ${ }^{1}$ \\ Alejandro Noyola Guadarrama ${ }^{1}$ Pamela Alcántara Maya ${ }^{2}$
}

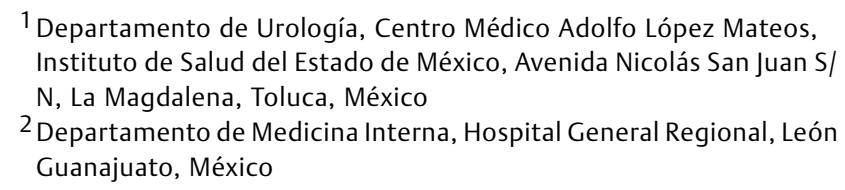

Address for correspondence Enrique Omar Piñón Solis, MD, Avenida Nicolás San Juan S/N, La Magdalena, Toluca, Código Postal: 50160, México (e-mail: Eopinon@hotmail.com).

Urol Colomb 2020;29:43-47.

\section{Resumen}

\section{Palabras clave}

- litiasis ureteral

- ureter inferior

- proteína C reactiva

- albúmina

- tratamiento médico expulsivo

- tamsulosina
Introducción La litiasis ureteral es responsable del $20 \%$ de casos de urolitiasis, el cólico renal afecta negativamente la calidad de vida, el mayor dilema es el elegir entre medidas conservadoras y cirugía. La mayoría de los litos ureterales de tercio distal menor de $6 \mathrm{~mm}$, pueden pasar espontáneamente con terapia conservadora. Sin embargo, ella se asocia a incomodidad, infecciones y ausencia laboral. La proteína $C$ Reactiva (PCR) se ha utilizado como predictor en la expulsión de esos litos, además se introduce el uso de la albúmina como nuevo marcador de predicción.

Objetivo El objetivo es analizar el valor predictivo de PCR y albúmina para la expulsión de litos ureterales de tercio inferior de $6-10 \mathrm{~mm}$.

Métodos Se realizó un estudio prospectivo en pacientes que presentaron cólico renal secundario a litiasis ureteral distal 6-10 Mm, los cuales recibieron tratamiento médico expulsivo durante 4 semanas, hasta la expulsión del lito o la necesidad de tratamiento quirúrgico en que se determinó punto de corte de PCR y albúmina por medio de una curva COR.

Resultados 78 pacientes se enrolaron en el estudio, el paso espontáneo fue de $55,1 \%$ y el restante requirió de intervención quirúrgica, el punto de corte para PCR fue $5,95 \mathrm{mg} / \mathrm{L}$ y de $2,75 \mathrm{~g} / \mathrm{dl}$ para albúmina.

Conclusión El PCR es un parámetro predictivo en la expulsión de litos ureterales de tercio inferior en pacientes muy seleccionados. Se obtiene el siguiente punto de corte para predecir la eliminación del lito $(5,95 \mathrm{mg} / \mathrm{L})$ y se propone la albúmina como un nuevo parámetro bioquímico. received

February 20, 2019

accepted

August 5, 2019
DOI https://doi.org/

$10.1055 / \mathrm{s}-0039-1697011$.

ISSN 0120-789X.

e ISSN 2027-0119.
Copyright $(2020$, Sociedad Colombiana License terms de Urología. Publicado por Thieme Revinter Publicações Ltda., Rio de Janeiro, Brazil. Todos los derechos reservados.

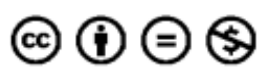




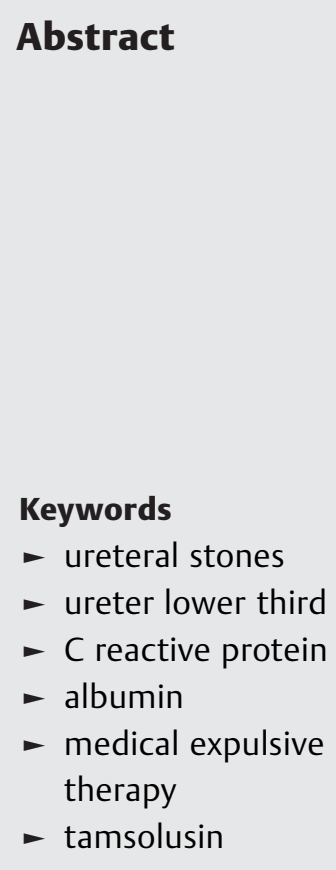

Introduction Ureteral stones is responsible for $20 \%$ of cases of urolithiasis, renal colic negatively affects quality of life, the main dilemma is choosing between conservative measures and surgery. Most ureteral stones of the distal third smaller than $6 \mathrm{~mm}$ can pass spontaneously with conservative therapy. However, this is associated with discomfort, infections. C Reactive protein (CRP) has been used as a predictor in the expulsion of these stones, and the use of albumin as a new marker of prediction is also introduced.

Objective The objective is to analyze the predictive value of CRP and albumin for the expulsion of ureteral stones of the lower third of $6-10 \mathrm{~mm}$

Methods A prospective study was performed in patients who presented renal colic secondary to distal ureteral lithiasis $6-10 \mathrm{~mm}$ and who received medical expulsive treatment for 4 weeks, until the expulsion of the stone or the need for surgical treatment, PCR cut off point was determined and albumin by means of a ROC curve. Results 78 patients enrolled in the study, spontaneous passage was $55.1 \%$ and the remaining required surgical intervention, the cut-off point for PCR was $5.95 \mathrm{mg} / \mathrm{L}$ and $2.75 \mathrm{~g} / \mathrm{dl}$ for albumin.

Conclusion CRP is a predictive parameter in the expulsion of lower third ureteral stones in highly selected patients. The following cut off point is obtained to predict the elimination of lithium $(5.95 \mathrm{mg} / \mathrm{L})$ and albumin is proposed as a new biochemical parameter.

\section{Introducción}

Los litos ureterales representan alrededor del $20 \%$ de toda la urolitiasis $^{1}$ y alrededor del $70 \%$ de ellos se encuentran en el tercio distal en el momento de su presentación. ${ }^{2}$ Afecta en su mayoría a los hombres, en una proporción hombre mujer de 2-3:1.,4 El manejo de la litiasis ureteral específicamente en tercio inferior sigue siendo controvertido, las alternativas terapéuticas consisten en tratamiento conservador e invasivo por medio de ureteroscopía y ureterolitotomía abierta o laparoscópica. ${ }^{5}$

El tratamiento médico se considera simple y rentable pero puede condicionar una alteración de la función renal, urosepsis y cólicos renales continuos, así como gastos económicos, incertidumbre y pérdida laboral en el paciente ${ }^{1}$ La Asociación Europea de Urología (AEU) en 2015 hace mención que litos ureterales de menos de $6 \mathrm{~mm}$ pueden tener un paso espontáneo a través del uréter. La AEU no recomienda MET para litos mayores de $10 \mathrm{~mm}$ debido a la baja probabilidad del paso espontáneo del lito. ${ }^{6,7}$

Se considera de manera clásica que el tamaño del lito medido es la variable más significativa que afecta la probabilidad de expulsión espontánea del lito ureteral, la tasa de expulsión espontánea es de 71-98\% para litos menores de $5 \mathrm{~mm}$ y mayores de $5 \mathrm{~mm}$ en 25 al $51 \%{ }^{1}$ La proteína c reactiva (PCR) es una proteína pentamérica que se encuentra en el plasma sanguíneo, se considera como un reactante de fase aguda, sintetizada principalmente en el hígado y su producción no fluctúa a lo largo del día, no se modifica por la ingesta de alimentos, y el nivel máximo se alcanza entre los 2 y los 3 días después del estímulo agudo, disminuyendo rápidamente después, lo que explica por qué solo una determinación de PCR en suero puede ser valorable. ${ }^{8-10}$ Existen diversas condiciones que modifican su producción al elevarla o disminuirla tales como la diabetes, cáncer, infección y alteraciones hepáticas. ${ }^{8,9}$ La albúmina en patología urológica presenta escasa información y se considera marcador inflamatorio negativo. ${ }^{11}$

PCR se considera factor bioquímico para determinar su expulsión. Aldaqadossi evaluó 235 pacientes y añadió la presencia de hidronefrosis así como leucocitos y neutrófilos como factor para el fracaso en la eliminación de litos, estimó un punto de corte de PCR de $21,9 \mathrm{mg} / \mathrm{l}$ (sensibilidad del 78,6\%, especificidad $89,3 \%$ ) realizó dos grupos y el primer grupo (54,9\%) logró expulsión del lito. ${ }^{1}$

El objetivo del estudio es analizar el valor predictivo de PCR y albúmina para expulsión de litos de 6-10 mm en tercio inferior del uréter.

\section{Métodos}

Se realizó un estudio prospectivo, observacional y analítico. Se incluyeron pacientes con cólico renal agudo debido a litiasis ureteral inferior en nuestro hospital del 1 de Noviembre del 2017 al 10 de Agosto del 2018, se incluyeron pacientes mayores de 18 años y menores de 80 años que presentaban lito en uréter inferior diagnosticado por tomografía simple de $6-10 \mathrm{~mm}$, lito ureteral único, que recibían MET y que autorizaban a formar parte del estudio mediante un consentimiento informado.

Se excluyeron pacientes con enfermedades inflamatorias, infecciones agudas, embarazadas, diabetes mellitus e hipertensión arterial, monorrenos funcional o anatómica, uropatía obstructiva bilateral, ingesta de esteroides, cáncer urológico y no urológico, insuficiencia hepática, ingesta de anticonceptivos, sangrado de tubo digestivo activo, riñón trasplantado, que deseaban tratamiento quirúrgico de inmediato o con dolor que no remiten al tratamiento conservador y pérdida del seguimiento. 
Se solicitó la aprobación del comité de ética del hospital, para posteriormente en el área de urgencias, tomar muestra de sangre periférica para la determinación de PCR, albúmina y biometría hemática previo a la medicación realizada por el laboratorio del hospital. Posteriormente se inició el manejo estandarizado: AINE (Diclofenaco Intravenoso), 4 semanas a base de tamsulosina $0,4 \mathrm{mg}$ vía oral cada 24 horas y AINE ambulatorio en caso de dolor e ingesta abundantes líquidos (más de dos litros de agua) diariamente.

Se realizó una tomografía simple de abdomen con cortes axiales y coronales en el servicio de radiología y se incluyeron los litos de 6 a $10 \mathrm{~mm}$ localizados en el uréter inferior (por debajo de la articulación sacro iliaca). Una vez diagnosticado se invitó al paciente por medio de un consentimiento bajo información a participar en el estudio.

Se determinaron los factores demográficos, episodios de dolor, número de visitas a urgencias previo al estudio y a las 4 semanas, así como la expulsión del lito, factores bioquímicos $\mathrm{y}$ factores radiológicos.

El total de los pacientes fue seguido durante un máximo de 4 semanas y a las 4 semanas, se realizó tomografía simple de abdomen, observando la ausencia o presencia del lito, en caso de que persistiera el lito se canalizó para tratamiento quirúrgico, se realizó el análisis de los datos en el programa SPSS Statistics 23.0 (IBM), el tamaño de la muestra se realizó mediante apoyo bioestadístico y se utilizaron medias, chi cuadrada para variables nominales y U de Mann Whitney para variables numéricas, así como análisis multivariado usando regresión logística y curva COR (Característica Operativa del Receptor) para determinar punto de corte, especificidad y sensibilidad para PCR y albúmina.

\section{Resultados}

Se enrolaron 109 pacientes con cólico renal secundario a litiasis ureteral de tercio inferior que cumplían con criterios de inclusión, 78 completaron el estudio y 31 abandonaron el estudio 14 sepsis y 17 por dolor. La media en cuanto a la edad fue de 44,92 años y la relación hombre-mujer fue 1,43:1. Más frecuente en los pacientes de más de 40 años (59\%) versus menos de 40 años (41\%) pero la expulsión de los litos fue más frecuente en mayores de 40 años ( 15 pacientes versus 28 que son mayores de 40 años).

Se dividieron los pacientes en dos grupos, el primer grupo (Grupo 1) se conformó por los pacientes que expulsaron el lito y el grupo 2 por los que no lo expulsaron, el Grupo 1 $(55,1 \%)$ y el Grupo 2 (44,9\%). Hubo 2 pacientes con antecedente de ureteroscopías de el grupo 1.

En la - Tabla 1 se muestran las características demográficas y de laboratorio. En la - Tabla 2 se muestran las medias del tamaño del lito en su corte axial y coronal así como de la pared ureteral y el diámetro ureteral proximal en ambos grupos.

La hidronefrosis se presentó en $40(51,3 \%)$ pacientes, 22 (55\%) en grupo 1 versus 18 (45\%) del grupo 2, el lado ureteral más frecuente fue el derecho $40(51,3 \%)$ versus 38 $(48,7 \%)$ al igual que en el grupo 1 (60,5\% versus $39,5 \%)$, sin embargo, en el grupo 2, fue el izquierdo (60\% versus $40 \%$ )
Tabla 1 Características demográficas y de laboratorio

\begin{tabular}{|c|c|c|c|}
\hline Variable & Grupo 1 & Grupo 2 & Valor $p$ \\
\hline Número & $43(55,1 \%)$ & $35(44,9 \%)$ & \\
\hline Media PCR (Mg/I) & $5,7 \pm 2,6$ & $9,1 \pm 6,7$ & 0,001 \\
\hline $\begin{array}{l}\text { Media Leucocitos } \\
\text { (Número } \times 10^{3} / \mathrm{dl} \text { ) }\end{array}$ & $9,1 \pm 2,7$ & $10,3 \pm 3,2$ & 0,001 \\
\hline $\begin{array}{l}\text { Media } \\
\text { Neutrófilos(\%) }\end{array}$ & $66,8 \pm 17,8$ & $70,0 \pm 19,3$ & $<0,001$ \\
\hline $\begin{array}{l}\text { Media Creatinina } \\
\text { Sérica }(\mathrm{mg} / \mathrm{dl})\end{array}$ & $1,1 \pm 0,3$ & $1,2 \pm 0,3$ & 0,157 \\
\hline $\begin{array}{l}\text { Media Albumina } \\
(\mathrm{g} / \mathrm{dl})\end{array}$ & $3,9 \pm 0,7$ & $3,1 \pm 1,0$ & 0,025 \\
\hline $\begin{array}{l}\text { Eritrocitos en el } \\
\text { Examen General } \\
\text { de Orina (Sí/No) }\end{array}$ & $(21 / 22)$ & $(25 / 10)$ & 0,013 \\
\hline Variable & Grupo 1 & Grupo 2 & Valor $p$ \\
\hline Número & $43(55.1 \%)$ & $35(44,9 \%)$ & \\
\hline Media edad & $44,98( \pm 11.9)$ & $44,86( \pm 10)$ & 0,002 \\
\hline $\begin{array}{l}\text { Género } \\
\text { (Hombre/Mujer) }\end{array}$ & $28 / 15$ & $18 / 17$ & 0,222 \\
\hline Tabaquismo (\%) & $10(23,3 \%)$ & $8(22,9 \%)$ & 0,967 \\
\hline $\begin{array}{l}\text { Uso AINES durante } \\
\text { el estudio (\%) }\end{array}$ & $20(46.5 \%)$ & $13(37.1 \%)$ & 0,405 \\
\hline $\begin{array}{l}\text { Episodios de } \\
\text { dolor durante } \\
\text { el estudio (\%) }\end{array}$ & $\begin{array}{l}0(23 / 53.5 \%) \\
1(18 / 41.9 \%) \\
2(2 / 4.7 \%)\end{array}$ & $\begin{array}{l}0(16 / 45.7 \%) \\
1(13 / 37.1 \%) \\
2(6 / 17.1 \%)\end{array}$ & 0,194 \\
\hline $\begin{array}{l}\text { Ingresos a } \\
\text { urgencias (\%) }\end{array}$ & $2(4.7 \%)$ & $10(28.6 \%)$ & 0,064 \\
\hline
\end{tabular}

Tabla 2 Características radiológicas

\begin{tabular}{|l|l|l|l|}
\hline Variable & Grupo 1 & Grupo 2 & Valor $p$ \\
\hline Número & $43(55.1 \%)$ & $35(44.9 \%)$ & \\
\hline Hidronefrosis (\%) & $22(51.1 \%)$ & $18(51.4 \%)$ & 0,981 \\
\hline $\begin{array}{l}\text { Lateralidad } \\
\text { (Derecho/Izquierdo) }\end{array}$ & $(26,17)$ & $(14,21)$ & 0,072 \\
\hline $\begin{array}{l}\text { Media Diámetro } \\
\text { axial del lito (Mm) }\end{array}$ & $6,1 \pm 0.4$ & $6,8 \pm 1.3$ & $\mathbf{0 , 0 3 7}$ \\
\hline $\begin{array}{l}\text { Media Diámetro } \\
\text { coronal del lito (Mm) }\end{array}$ & $5,1 \pm 2.1$ & $5,8 \pm 2.1$ & $\mathbf{0 , 0 0 6}$ \\
\hline $\begin{array}{l}\text { Media pared del } \\
\text { ureter (Mm) }\end{array}$ & $1,1 \pm 0.5$ & $1,0 \pm 0.4$ & $\mathbf{0 , 0 0 5}$ \\
\hline $\begin{array}{l}\text { Media Diámetro } \\
\text { proximal al lito (Mm) }\end{array}$ & $6,3 \pm 2.6$ & $6,9 \pm 2.4$ & $\mathbf{0 , 0 0 2}$ \\
\hline
\end{tabular}

y solo 2 pacientes presentaron como variante anatómica reimplante ureteral del grupo 1.

Utilizando un análisis de regresión logística se determinó cuál presentó una correlación fuerte con respecto a la expulsión. - Tabla 3.

Se utilizó una curva COR para determinar un punto de corte en la predicción de expulsión de litos, con una área bajo la curva (AUC) para PCR de $20 \%$ se determinó que un valor sérico de PCR mayor de 5,95 Mg/L existe una especificidad de $91,4 \%$ y una sensibilidad de 53,5\% de fracaso en la expulsión 
Tabla 3 Factores potenciales de predicción en la expulsión de litos ureterales distales

\begin{tabular}{|l|l|}
\hline Variable & OR (95\% de I.C) \\
\hline Edad & $0,993(0,926-1,064)$ \\
\hline PCR & $0,817(0,642-1,040)$ \\
\hline Leucocitos & $0,981(0,740-1,301)$ \\
\hline Neutrófilos & $0,959(0,908-1,012)$ \\
\hline Albúmina & $2,792(1,180-6,608)$ \\
\hline $\begin{array}{l}\text { Eritrocitos en el Examen } \\
\text { General de Orina }\end{array}$ & $0,997(0,988-1,007)$ \\
\hline Diámetro Axial & $0,212(0,030-1,484)$ \\
\hline Diámetro Coronal & $0,823(0,566-1,197)$ \\
\hline Diámetro de la pared del uréter & $8,615(.904-82.091)$ \\
\hline Diámetro del ureter proximal al lito & $1,051(0,736-1,500)$ \\
\hline
\end{tabular}

del lito y con PCR menor de 5,95 Mg/L una especificidad 53,5\% y sensibilidad del 91,4\% de expulsión del lito. -Figura 1.

Para determinar el valor predictivo de albúmina se utilizó curva COR con un AUC de 71,3\%, se determinó que un valor mayor de 2,75 g/Dl tendrá una sensibilidad del 90\% y una especificidad de 66\% en la expulsión esos litos. - Figura 2.

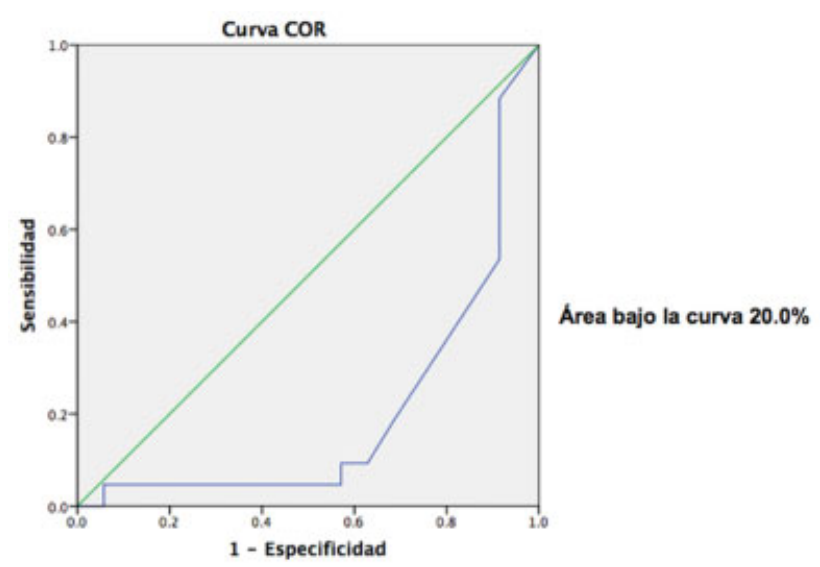

Fig. 1 Curva COR (Característica Operativa del Receptor) para PCR.

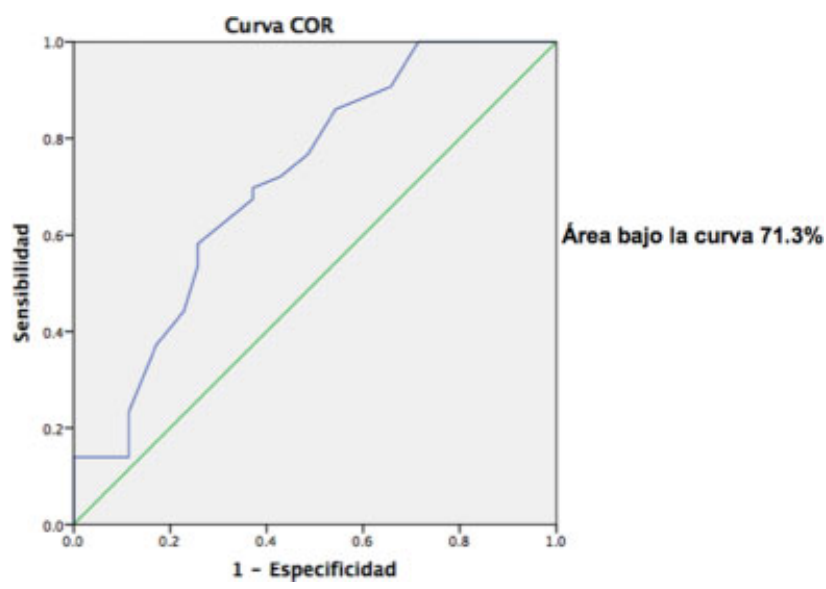

Fig. 2 Curva COR para albúmina.

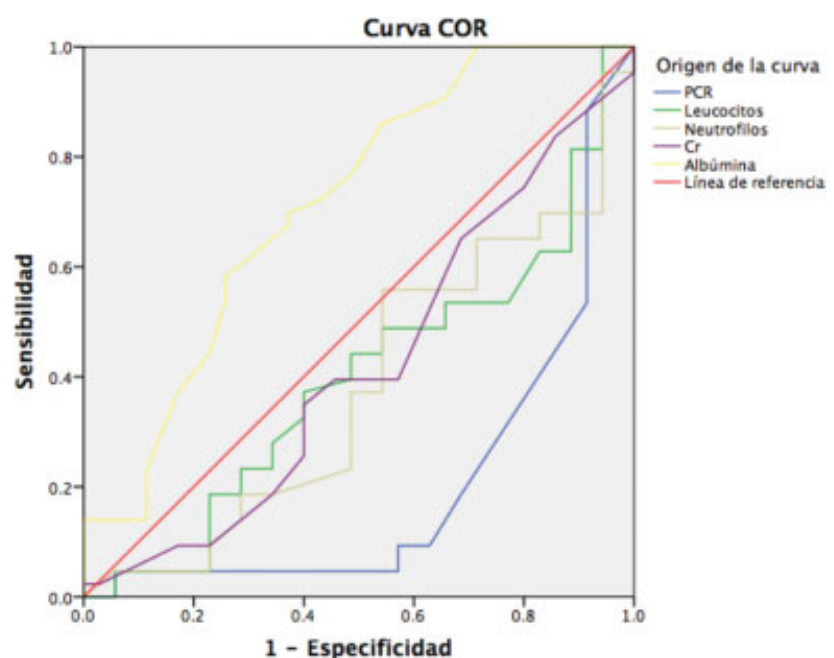

Fig. 3 Curva COR para PCR, Leucocitos, neutrófilos, creatinina y albúmina.

Por último, se determinó la curva COR de PCR, albúmina, leucocitos, neutrófilos y creatinina y se observa inversión de la curva de leucocitos, neutrófilos, creatinina y PCR con respecto a la albúmina. -Figura 3.

\section{Discusión}

En el uréter se encuentran adrenoreceptores alfa 1D y alfa 1A, que son más abundantes en el uréter distal y desempeñan un papel importante en la fisiología ureteral inferior a través de un efecto sobre el músculo detrusor de la vejiga y la contracción del músculo liso ureteral, ${ }^{2,12}$ por lo cual se justifica el uso de MET. ${ }^{13}$ Tamsulosina es un bloqueador alfa selectivo con afinidad tanto para $1 \mathrm{~A}$ como para $1 \mathrm{D} .^{12}$ MET presenta una tasa de expulsión del $82 \%$ versus $67 \%$ del placebo. ${ }^{14}$ A pesar de ello, el tratamiento médico debe interrumpirse en caso de complicaciones tales como infección activa, dolor refractario o deterioro de la función renal. $^{13}$

La elección del tratamiento para litiasis ureteral de tercio inferior es difícil. Varios estudios han demostrado que MET es efectivo en la expulsión de litos ureterales de tercio inferior porque incrementa el paso espontáneo del lito, sin embargo, el éxito de MET es determinado por varios factores propios del paciente, de laboratorio y radiológicos, motivo por el cual se dividieron los factores en esos 3 grupos. Park analizó litos inferiores a $8 \mathrm{~mm}$ y también incluyó la cuenta de leucocitos y neutrófilos como predictores, la limitación principal fue el tiempo de 8 semanas lo que exponía al paciente a un mayor riesgo de episodios de dolor e ingreso a urgencias por ese motivo, daño renal irreversible e infecciones de vías urinarias de repetición, además incluyó las 3 porciones ureterales. ${ }^{5,15}$ En un estudio de 115 pacientes en Egipto, se valoró el papel de PCR y los neutrófilos como factor predictivo, sin embargo, en este estudio, no demostraron un punto de corte para PCR. ${ }^{16}$ En el estudio de Özcan, se evaluaron 251 pacientes de los cuales 53,8\% (135 pacientes) presentaron expulsión del lito, también se 
determinó punto de corte de PCR. La limitante de este estudio es la utilización de diferentes alfa bloqueadores. ${ }^{17}$

En nuestro estudio fue más frecuente el grupo que expulsó el lito con MET $(55,1 \%)$ muy similar al reporte global de probabilidad de expulsión que es de $65 \%$. Sfoungaristos informó que el lado izquierdo era el más probable en el paso espontáneo del lito, en este estudio se demostró que la expulsión es más frecuente del lado derecho. ${ }^{18}$ Con respecto a las características demográficas se observó que la edad era la más significativa coincidiendo con el estudio de Özcan y con respecto a las características de laboratorio en nuestro estudio se observó que la cantidad de leucocitos séricos y neutrófilos fueron significativos, no así la creatinina sérica y con respecto a las radiológicas, el diámetro axial del lito una media de $6,1 \mathrm{~mm}$ de los pacientes que presentaron expulsión con significancia estadística, sin embargo, también el diámetro coronal del lito, el tamaño de la pared ureteral y el diámetro proximal también eran significativos. ${ }^{17}$

La labilidad de PCR es bien conocida, motivo por el cual los pacientes de este estudio fueron muy seleccionados. Por esa razón, se propuso un nuevo bio marcador de inflamación como lo es la albúmina, con disponibilidad más amplia y menor costo. PCR como variable aislada presentó significancia estadística, pero al realizar un análisis de regresión logística se obtuvo a la albúmina con correlación más fuerte $(p=0,019)$. La albúmina basada en los estudios de marcador de inflamación se propone como nuevo biomarcador, sin embargo, es escasa la información en la aplicación de esa patología urológica en la literatura mundial. A diferencia de la literatura mundial, se obtiene un punto de corte mas bajo para PCR y se agrega albúmina como predictor de expulsión.

La principal ventaja de este estudio es que es un estudio prospectivo. Sus limitaciones fueron la selección de los pacientes ya que tenían que cumplir los criterios de inclusión, por lo cual la cantidad de pacientes estudiados no es amplia como en los estudios previamente comentados, además de que una cantidad importante de pacientes abandonaron el estudio por procesos infecciosos agregados durante el estudio o por dolor incontrolable.

\section{Conclusiones}

La PCR pudiera ser un parámetro predictor en la expulsión de litos ureterales de tercio inferior en pacientes bien seleccionados, así como definir qué pacientes se beneficiarán con MET o requerirán cirugía temprana de urgencia.

Se obtiene el siguiente punto de corte en el valor sérico de PCR para predecir la eliminación del lito $(5,95 \mathrm{mg} / \mathrm{L})$ y se propone la albúmina como un nuevo parámetro bio químico para predecir la expulsión de esos litos.

\section{Conflicto de Intereses}

Los autores declaran no tener ningún conflicto de intereses.

\section{Referencias}

1 Aldaqadossi HA. Stone expulsion rate of small distal ureteric calculi could be predicted with plasma C-reactive protein. Urolithiasis 2013;41(03):235-239

2 Kc HB, Shrestha A, Acharya GB, Basnet RB, Shah AK, Shrestha PM. Tamsulosin versus tadalafil as a medical expulsive therapy for distal ureteral stones: A prospective randomized study. Investig Clin Urol 2016;57(05):351-356

3 Millán F, Gracia S, Sánchez-Martín FM, Angerri O, Rousaud F, Villavicencio $\mathrm{H}$. Un nuevo enfoque en el análisis de la litiasis urinaria en función de la combinación de sus componentes: experiencia con 7.949 casos. Actas Urol Esp 2011;35(03):138-143

4 Pickard R, Starr K, MacLennan G, et al. Medical expulsive therapy in adults with ureteric colic: a multicentre, randomised, placebocontrolled trial. Lancet 2015;386(9991):341-349

5 Dell'Atti L, Papa S. Ten-year experience in the management of distal ureteral stones greater than $10 \mathrm{~mm}$ in size. G Chir 2016;37 (01):27-30

6 Beach MA, Mauro LS. Pharmacologic expulsive treatment of ureteral calculi. Ann Pharmacother 2006;40(7-8):1361-1368

7 Bader MJ, Eisner B, Porpiglia F, Preminger GM, Tiselius HG. Contemporary Management of Ureteral Stones. Eur Urol 2012; 61(04):764-772. Rev(2016)

8 Angulo JC, Gaspar MJ, Rodríguez N, García-Tello A, Torres G, Núñez $\mathrm{C}$. The value of $\mathrm{C}$-reactive protein determination in patients with renal colic to decide urgent urinary diversion. Urology 2010;76 (02):301-306

$9 \mathrm{Kim}$ JH, Doo SW, Yang WJ, Song YS, Kwon SS. Association Between High-sensitivity C-reactive Protein and Lower Urinary Tract Symptoms in Healthy Korean Populations. Urology 2015;86 (01):139-144

10 Amezcua-Guerra LM, Springall del Villar R, Bojalil Parra R. Proteína $C$ reactiva: aspectos cardiovasculares de una proteína de fase aguda. Arch Cardiol Mex 2007;77(01):58-66

11 Carrasco-Valiente J, Anglada-Curado FJ, Aguilar-Melero P, et al. Estado de los marcadores de fase aguda y estrés oxidativo en los enfermos con litiasis de la vía urinaria. Actas Urol Esp 2012;36 (05):296-301

12 Kumar S, Jayant K, Agrawal MM, Singh SK, Agrawal S, Parmar KM. Role of tamsulosin, tadalafil, and silodosin as the medical expulsive therapy in lower ureteric stone: a randomized trial (a pilot study). Urology 2015;85(01):59-63

13 Türk C, Petřík A, Sarica K, et al. EAU Guidelines on Diagnosis and Conservative Management of Urolithiasis. Eur Urol 2016;69(03): 468-474

14 Al-Ansari A, Al-Naimi A, Alobaidy A, Assadiq K, Azmi MD, Shokeir AA. Efficacy of tamsulosin in the management of lower ureteral stones: a randomized double-blind placebo-controlled study of 100 patients. Urology 2010;75(01):4-7

15 Park CH, Ha JY, Park CH, Kim CI, Kim KS, Kim BH. Relationship Between Spontaneous Passage Rates of Ureteral Stones Less Than $8 \mathrm{~mm}$ and Serum C-Reactive Protein Levels and Neutrophil Percentages. Korean J Urol 2013;54(09):615-618

16 Elsayed M, Radwan M, Elkhamisy N, Eishelkh K, Abo El-enen M, Naglah S, et al. Relationship between spontaneous passage rates of ureteral stones less than $10 \mathrm{~mm}$ and serum C-Reactive Protein level and neutrophil percentage. JUrol Supplement 2016 May; 195 (4S): 1171

17 Özcan C, Aydoğdu O, Senocak C, et al. Predictive Factors for Spontaneous Stone Passage and the Potential Role of Serum CReactive Protein in Patients with 4 to $10 \mathrm{~mm}$ Distal Ureteral Stones: A Prospective Clinical Study. JUrol 2015;194(04):1009-1013

18 Sfoungaristos S, Kavouras A, Perimenis P. Predictors for spontaneous stone passage in patients with renal colic secondary to ureteral calculi. Int Urol Nephrol 2012;44(01):71-79 